\title{
Idiopathic gastric infarction in childhood
}

\author{
Elizabeth Wanek ${ }^{1}$, Keith T. Oldham ${ }^{1,3}$, Theodore Z. Polley Jr ${ }^{1,3}$, and S. Kottamatsu ${ }^{2}$ \\ Departments of ' Surgery and ${ }^{2}$ Diagnostic Radiology, Henry Ford Hospital, Detroit, Michigan, and the ${ }^{3}$ Section of Pediatric \\ Surgery, University of Michigan School of Medicine, Ann Arbor, MI 48109, USA
}

\begin{abstract}
The case of a 6-year-old female with gastric infarction is presented. Despite a careful evaluation, no etiology could be determined in this child or, retrospectively, in several similar children described by other authors in the past. Vascular compromise was present although it is not possible to know whether this was a primary or a secondary event. It is important to recognize that gastric infarction can occur in children without obvious explanation.
\end{abstract}

Key words: Gastric infarction - Gastric necrosis - Gastric gangrene

\section{Introduction}

Infarction of the stomach is a rare event in children. A 6-year-old child who presented with clinical evidence of an abdominal catastrophe and systemic sepsis secondary to idiopathic gastric infarction is presented. An emergency total gastrectomy with esophagoduodenostomy was done and recovery was uneventful. No etiology was apparent.

The generous blood supply and favorable anatomy of the stomach tend to protect against the trauma, infections, and vascular accidents that commonly afflict the more distal gastrointestinal (GI) tract. Gastric infarction may result, however, from disruption of its blood supply secondary to gastric volvulus, paraesophageal hernia, paraduodenal hernia, diaphragmatic hernia, or eventration of the diaphragm $[4,5,9,10,13]$. In addition, gross gastric distension associated $[4,5$, $9,10,13,15]$ with lesions such as pyloric stenosis

Offprint requests to: K. T. Oldham is known to occasionally cause thrombosis of the intramural blood supply of the stomach with subsequent infarction [6]. Direct injury from acid or alkali ingestions may destroy all or part of the stomach $[1,9,14]$. Synergistic necrotizing gangrene of the stomach is associated with a variety of aerobic and anaerobic bacterial organisms [12]. These etiologies all seem intuitive; however, a careful review of reported cases and the case detailed here suggest that gastric infarction, although rare, may have no obvious etiology at the time of presentation $[7,9]$.

\section{Case report}

A 6-year-old Caucasion female with mild cerebral palsy and a well controlled seizure disorder secondary to neonatal menigitis presented for evaluation of an obvious intra-abdominal catastrophe. She had been an active, healthy child until $6 \mathrm{~h}$ prior to admission when she awoke from sleep, vomited, and suddenly became cyanotic. She was taken to a hospital emergency room for evaluation. Her foster mother noted upper abdominal distension for the first time at the time of transport. Initial resuscitation consisted of endotracheal intubation, placement of peripheral intravenous lines, and transfer to our institution. Upon arrival, she was unresponsive, with a systolic blood pressure of $60 \mathrm{~mm} \mathrm{Hg}$. She had obvious circulatory collapse with mottled, cool, and poorly perfused extremities with a rigid, distended upper abdomen. A nasogastric tube was placed into the stomach and returned dark brown, feculent material but the abdomen remained rigid. A chest X-ray demonstrated right upper lobe pneumonia consistent with aspiration. Plain abdominal radiographs (Fig. 1) showed an obvious pneumoperitoneum and a peculiar left upper quadrant image with a double air shadow outlining the gastric wall. This was consistent with either intramural or extramural air. The white blood cell (WBC) count was 7,700 cells $/ \mathrm{ml}$.

Following fluid resuscitation, placement of arterial and central venous pressure catheters, and administration of broad-spectrum antibiotics, she was taken to the operating room for exploratory laparotomy. At laparotomy she had a massively dilated, infarcted stomach with transmural necrosis 


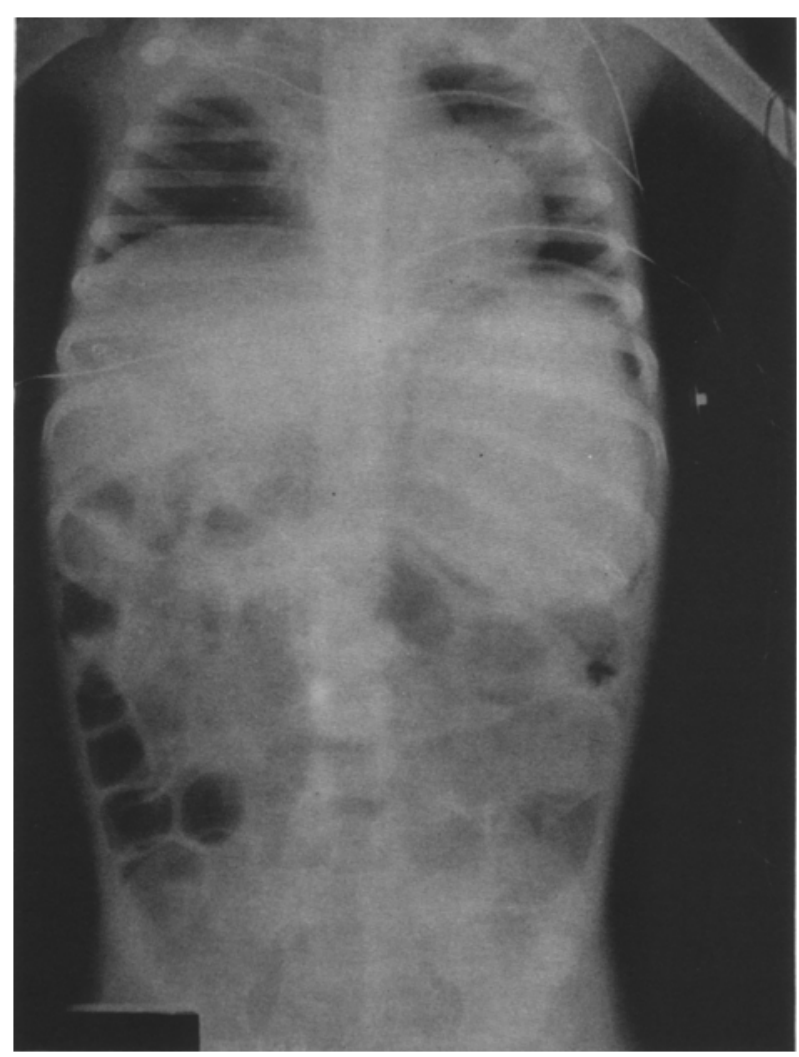

Fig. 1. The plain abdominal radiograph demonstrates pneumoperitor eum and extensive intramural air within the gastric wall. A right upper lobe pneumonia presumed to be the result of aspiration is also present

and intranural air. Other than distension and the transmural necrosis, the stomach was anatomically normal. Phrenoesophageal, cuodenal, short gastric, and gastrocolic attachments were all ncrmal. The area of infarction extended from the gastroesopha eal junction to the pylorus. Venous and arterial thrombosis had occured in the gastroepiploic, short gastric, and left gastric vessels. There was no volvulus, diaphragmatic hernia, paraesophageal hernia, eventration of the diaphragm, or gastric outlet obstruction. The line of demarcation at the proximal and distal margins of the infarcted stomach was very sharply $d \epsilon$ ined. The esophagus was normal both at laparotomy and at esophagoscopy immediately after the abdomen was closed.

In spice of obvious pneumoperitoneum by radiograph and when the peritoneum was opened, no free perforation of the stomach hid occurred. A total gastrectomy with bilateral truncal vagotomy was done. A viable $1.5-\mathrm{cm}$ anterior rim of pylorus was preserved. The posterior line of resection was through the midpotion of the duodenal bulb, thus removing the posterior half $\mathrm{c}:$ the pylorus. The esophageal transection was performed $1.0-2.0 \mathrm{~cm}$ proximal to the gastroesophageal junction. Reconstrustion was accomplished by end-to-end esophagoduodenostomy. Postoperatively, the patient recovered uneventfully from her septic shock and gastrectomy. She received a 2-week course of broad-spectrum antibiotic therapy to treat her aspirarion pneumonia and abdominal sepsis. She also received total parenteral hyperalimentation until an upper GI series demonstrated a patent anastomosis with passage of con- trast into the duodenum. She was discharged from the hospital 4 weeks after admission.

Pathological examination of the stomach confirmed transmural necrosis. The gastric wall had massive submucosal emphysema with focal areas of hemorrhage. The radiographic appearance of the stomach in Fig. 1 was clearly the result of this massive circumferential submucosal dissection by intramural air. Microscopic examination of the mucosa showed diffuse necrosis with some preservation of the epithelium and glands in the antrum. No bacteria were seen in the submucosa and there was minimal inflammatory cell infiltration. The intraoperative peritoneal fluid cultures grew only a lactobacillus species.

At 1 year follow-up, she has resumed her previous activities and her weight is stable at the pre-illness level. She takes frequent, small oral feedings and receives parenteral vitamin $\mathrm{B}_{12}$ and iron, oral folic acid, and a multivitamin supplement.

\section{Discussion}

In 1965, Moore reported the results of a survey of American and British pediatric surgeons with a total experience of 113 gastric resections in children younger than 13 years of age; only 3 of these were total gastrectomies $[8,9]$. The most common indications were peptic ulcer disease (42), gastric perforation due to ingestion of toxic materials (13), gastric duplication (11), and benign or malignant neoplasms (14). Three of the gastric resections were done for idiopathic gastric necrosis and perforation, all in children less than 2 years of age. Although the overall operative mortality was $10 \%$, survivors had excellent or normal postoperative growth and development. In 1974, Kerstein et al. reported a case of gastric infarction and rupture in an 18-year-old girl secondary to psychogenic polyphagia and massive gastric dilatation [7]. Quak et al. reported survival after neonatal gastrectomy in a 2-day-old infant who had developed idiopathic, spontaneous gastric infarction and perforation [11].

Gastric volvulus is an important cause of gastric infarction in the pediatric population $[4,5$, 10]. This diagnosis can generally be made at laparotomy; the volvulus persists if it is tight enough to produce vascular occlusion and, additionally, the attachments of the stomach are more lax than normal. Acute synergistic bacterial necrotizing gastritis, although never reported in the pediatric population, has been implicated as a cause of transmural necrosis of the stomach [12]. The cause of the gastric infarction in this 6-year-old child remains unknown. There was no evidence of gastric volvulus at surgery; there was no intrinsic anatomic defect causing gastric outlet obstruction and no diaphragmatic, paraesophageal, or paraduodenal hernia. There was no acute inflammatory cell infiltrate or suppuration to suggest acute necrotiz- 
ing gastritis. There was no history or physical evidence to suggest the ingestion of some toxic substance and the esophagus was entirely normal. Acute gastric dilatation with venous thrombosis and secondary gangrene is possible. This, however, brings us no closer to establishing a specific etiology.

Bradley et al. reviewed the cases of ten adults after total gastrectomy for benign disease, and concluded that postoperative weight loss and malnutrition result primarily from diminished oral intake rather than malabsorption or dumping $[2,3]$. The surgical construction of a gastric reservoir did not necessarily improve intake in this series. Absence of a gastric reservoir was overcome by careful, small, frequent feedings. In. view of the emergency nature of this child's gastrectomy, no effort was made to construct a reservoir. She has learned to eat frequent small meals and is currently well, and there is no plan to construct a reservoir. She remains well 1 year after surgery.

\section{References}

1. Berry WB, Hall RA, Jordon GL (1965) Necrosis of the entire stomach secondary to ingestion of a corrosive acid. Am J Surg 109: 652

2. Bradley EL, Issacs J, Hersh T, Davidson ED, Millikan W (1975) Nutritional consequences of total gastrectomy. Ann Surg 182: $4115-4129$
3. Bradley EL, Isaacs J (1976) Postresectional anemia, a preventable complication of total gastrectomy. Arch Surg 111:844-848

4. Campbell JB (1979) Neonatal gastric volvulus. AJR 132: 723

5. Daghes M, MacMath TL, Seger DL (1984) Mesenteroaxial gastric volvulus in children. South Med J 77: 768-770

6. Fleming LB, Horton JA, Wagger J (1966) Spontaneous rupture of stomach. Rare complication of pyloric stenosis. Br J Surg 53: 384

7. Kerstein MD, Goldberg B, Panter B, Filston MD, Spiro H (1974) Gastric infarction. Gastroenterology 67: $1238-1239$

8. Moore TC (1964) Gastrectomy in infancy and childhood: I. Report of two cases of gastrectomy in early infancy. Ann Surg 160: 245

9. Moore TC (1965) Gastrectomy in infancy and childhood: II. Results of an international survey. Ann Surg 162: 91-99

10. Patel NM (1985) Chronic gastric volvulus: report of a case and review of literature. Am J Gastroenterol 80: 170-173

11. Quak SH, Joseph VT, Wong HB (1984) Neonatal total gastrectomy. Clin Pediatr 507-508

12. Strauss RJ, Friedman M, Platt N, Gassner W, Wise L (1978) Gangrene of the stomach: a case of acute necrotizing gastritis. Am J Surg 135: 253-257

13. Tellors $T H$, Papp C (1955) Strangulated diaphragmatic hernia with torsion of the stomach. Br J Surg 43: 289

14. Tinney DC, Chaunfer LL, Stafford ES (1960) Total gastrectomy in an infant made necessary by ingestion of tinning paint. Ann Surg 151: 891

15. Turner FW (1972) Gangrene and rupture of the stomach secondary to jejunal obstruction by an internal (paraduodenal) hernia: a case report. Can J Surg 15: 118-121

Accepted September 9, 1987 